\title{
COMBINATION OF TWO PSEUDOANEURYSMS IN A PATIENT 6 YEARS AFTER ASCENDING AORTA AND AORTIC VALVE REPLACEMENT
}

\author{
Radim Brat, Tomas Danek, Vaclav Maly
}

Department of Cardiac Surgery, University Hospital Ostrava, Czech Republic
e-mail: radim.brat@fnspo.cz

Received: January 26, 2007; Accepted: April 24, 2007

Key words: Pseudoaneurysm/Ascending aorta/Button technique

Background: We report successful treatment of a patient 6 years after ascending aorta and aortic valve replacement suffering from a combination of two pseudoaneurysms. The first of them originated from the coronary ostial suture line and the second pseudoaneurysm originated from the distal suture line.

Methods: We performed re-replantation of the left main trunk to the prosthesis and then we resected the pseudoaneurysm originating from the distal suture line and we replaced the entire aorta by a vascular graft.

Results: The postoperative convalescence was uneventful, the patient was discharged two weeks after the surgery. The patient is currently in a very good condition one year after the surgery.

Conclusions: Coronary ostial pseudoaneurysm in patients after ascending aorta and aortic valve replacement with the use of "button technique" is a quite rare situation. The combination of two pseudoaneurysms originating from different suture lines in one patient seems to be unique in literature reviews.

\section{INTRODUCTION}

The first successful replacement of the ascending aorta and aortic valve was performed in 1964 by Wheat ${ }^{1}$. Four years later, Bentall and De Bono ${ }^{2}$ described a technique for total aortic root replacement with a composite graft containing a prosthetic valve with side-to-end reimplantation of the coronary artery ostia. In 1981, Cabrol and associates ${ }^{3}$ modified the aortic root operation introducing a second tube graft connecting both coronary ostia and the main ascending aortic graft. This was inspired by the many complications of the original Bentall procedure. Later, in 1991, Kouchoukos et al. ${ }^{4}$ showed that his modification, the "open or button technique", for the reimplantation of the coronary arteries was safer in terms of a lower incidence of late false aneurysms.

Coronary ostial pseudoaneurysm in patients after ascending aorta and aortic valve replacement with the use of "button technique" is a quite rare situation and pseudoaneurysm originating from the distal suture line is a very rare late complication as well.

The combination of the pseudoaneurysm originated from the coronary ostial suture line and pseudoaneurysm originated from the distal suture line in one patient seems to be unique in literature reviews. We report successful treatment of such patient.

\section{CASE REPORT}

On August 10, 1998, a 53 years old male patient was admitted to a peripheral hospital due to an acute onset of severe chest pain for two hours. Echocardiography diag- nosed an aortic dissection, Stanford Type A, with aortic valve insufficiency grade IV and the diameter of the ascending aorta was $53 \mathrm{~mm}$. Chest CT revealed a thickened and dilated ascending aorta, aortic arch and descending aorta. An entry tear was found in the ascending aorta, the descending aorta and the aortic arch respectively.

However, the patient was referred to our hospital and he was transferred to the operating theatre where he underwent the Bentall operation using a deep hypothermic circulatory arrest. Cardiopulmonary bypass was established with an arterial line from the right femoral artery and venous line from the right atrium. The postoperative convalescence was uneventful except the revision of the right groin due to a lymphatic secretion. The postoperative echocardiography showed the aortic valve was functioning well. The patient was discharged three weeks after the surgery. An echocardiography one year after surgery was free from pathology.

In October 2000, he was admitted to the department of internal medicine in our hospital to be prepared for a scheduled orthopaedic procedure. Due to the patient's chest distress and the shortness of his breath, a coronary angiography was performed. This showed $80 \%$ stenosis of the left main trunk (LMT). An endovascular stent ACS DUET $4.0 \times 8 \mathrm{~mm}$ was put in place. As a secondary finding a small aneurysm in the place of the implantation of the left coronary was found.

After a short convalescence the patient underwent the scheduled orthopaedic surgery with no complications and in a fairly good condition. The echocardiography one year later showed the pseudoaneurysm with a diameter 11 x $15 \mathrm{~mm}$. On February, 2001 the patient underwent stentgraft placement procedure (Jomed $12 \mathrm{~mm}$ ) to the LMT 
because of an increase in the size of the pseudoaneurysm, but this did not solve the problem. He was discharged in good condition and with no signs of ischemic pain. Echocardiography, chest CT, and coronary angiography were made regularly once a year. Chest CT in 2004 revealed an increase in the size of the pseudoaneurysm (from $11 \times 15$ to $30 \times 20 \mathrm{~mm}$ ) and a follow-up found that the patient's general condition remained normal during the period 2001-2004.

But one year later, the patient suffered from continuous chest distress, CT scan confirmed that the diameter of the aneurysm was $37 \times 25 \mathrm{~mm}$ and the LMT was severely compressed by the aneurysm (Fig. 1). And another aneurysm originating from the distal anastomosis between prosthesis and aorta was found. Upon readmission echocardiography and coronary angiography were made and the patient was scheduled for a re-do operation.

In May 2005, the patient was admitted to our hospital for a re-do surgery under general anaesthesia. Cardiopulmonary bypass was initiated using cannulation of the right axillary artery and the right atrium. Cannulation of main pulmonary artery optimized the venous drainage. Before this the harvesting of the left saphenous vein and the LITA were done. A clamp was placed $1 \mathrm{~cm}$ above the distal anastomosis and below the aortic arch. The conduit was incised vertically and a pseudoaneurysm in communication between the false and the true lumen was detected. During the preparation of the prosthesis the pseudoaneurysm in the place of the insertion of the left coronary artery was opened. The LMT was completely separated from its insertion and the stent-graft stuck out from the LMT. Due to the difficulty of operating in this anatomical region, we changed our plan. Primarily we wanted to close the LMT and to establish CABG using vein grafting and LITA. We made re- replantation of the LMT to the prosthesis using suture and, the remaining pseudoaneurysm was filled with GRF glue. After this we made a partial resection of the pseudoaneurysm originating from the distal suture line and we covered the defect using a vascular graft. The postoperative convalescence was uneventful, the patient was discharged two weeks after the surgery.

The patient was followed up closely. The first year after the surgery he was free from dyspnoea or other complications. He was in a good condition. The CT scan confirmed normal flow in the LMT without any aneurysm and the ECHO study one year after the surgery revealed the same.

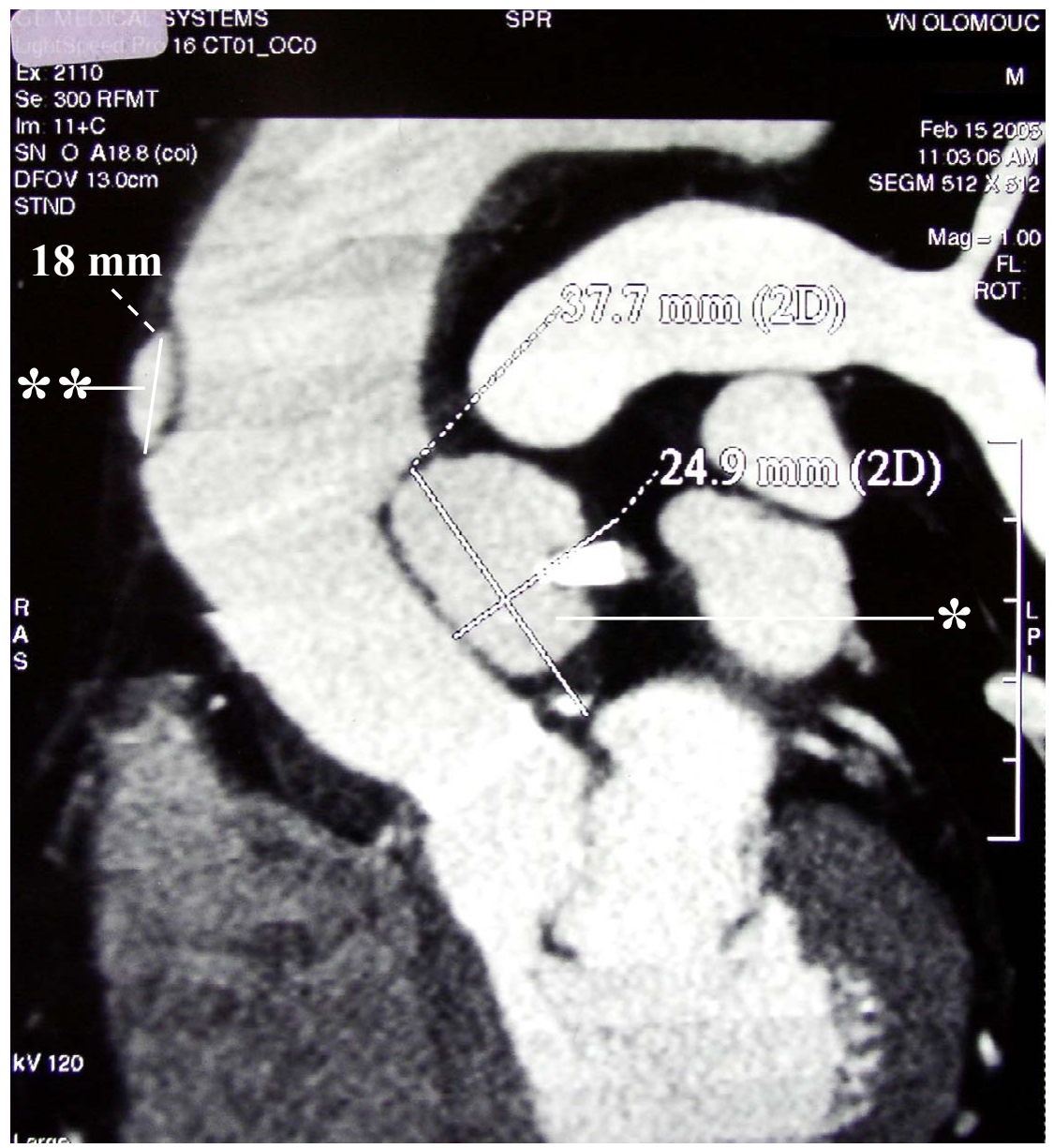

Fig. 1. Pre-operative CT scan showing the combination of pseudoaneurysm originating from the coronary ostial suture line $(*)$ and the pseudoaneurysm originating from the distal suture line $(* *)$. 


\section{DISCUSSION}

The incidence of pseudoaneurysm arising from the vascular graft-to-aorta anastomosis or coronary ostial anastomosis is very low. Strauch et $a .^{5}$ reported their results in a large group of patients (1475 patients with a total of 2281 anastomosis). The incidence of the suture line disruption was 1 per 191 patient-years, or 1 per 296 anastomosis-years. Milano et al. ${ }^{6}$ who reviewed 71 patients receiving a composite aortic conduit reported 4 patients $(6 \%)$ with anastomotic complications. In 2 a pseudoaneurysm developed at the distal aortic suture line and in 1 a pseudoaneurysm developed after the repair of an acute aortic dissection of the right coronary ostium. In 1 Marfan patient an aneurysm of the left coronary ostium developed. Such complications were unrelated to the surgical techniques used for reimplantation of the coronary ostia. Similar experience has been reported by Dossche and co-workers ${ }^{7}$ who identified 2 patients with pseudoaneurysm at the coronary ostial suture line. All these patients were primary operated for acute aortic dissection.

Low incidence of pseudoaneurysm at the composite graft has been reported also by Schachner et al. ${ }^{8}$ who reported this late complication in $3 \%$ in a series of 74 patients and by Ruvolo and co-workers ${ }^{9}$ who reported $0 \%$ incidence out of 105 patients.

Schepens and co-workers ${ }^{10}$ reported 4 patients with a pseudoaneurysm originated from the distal suture line in their series of 134 patients reoperated on the aortic root or ascending aorta.

The incidence of two pseudoaneurysms in one patient requiring reoperation is extremely low. Strauch and coworkers ${ }^{5}$ reported only 1 patient with pseudoaneurysm of the distal and proximal anastomosis in their large series of 1475 patients. Omeroglu et al. ${ }^{11}$ published a case report of two pseudoaneurysms originated from both coronary ostial anastomoses. But the combination of the pseudoaneurysm originated from the coronary ostial suture line and pseudoaneurysm originated from the distal suture line in one patient seems to be unique in a literature reviews.

Since 1997192 patients underwent thoracic aorta replacement in our institution and we have performed 531 anastomosis in these patients. Only 2 of these patients were reoperated because of pseudoaneurysm. One patient was reported above and the second one was reoperated because of a pseudoaneurysm at the left coronary ostium due to the infection two years after the primary operation.

\section{CONCLUSION}

Coronary ostial pseudoaneurysm in patients after ascending aorta and aortic valve replacement with the use of "button technique" is a quite rare situation. The combination of the pseudoaneurysm originated from the coronary ostial suture line and pseudoaneurysm originated from the distal suture line in one patient seems to be unique in literature reviews. We have reported successful treatment of such patient.

\section{REFERENCES}

1. Wheat MW Jr, Wilson JR, Bartley TD. Successful replacement of the entire ascending aorta and aortic valve. JAMA 1964; 188:7179 .

2. Bentall H, De Bono A. A technique for complete replacement of the ascending aorta. Thorax 1968; 23:338-9.

3. Cabrol C, Pavie A, Gandjbakhch I. Complete replacement of the ascending aorta with reimplantation of the coronary arteries. New surgical approach. J Thorac Cardiovasc Surg 1981; 81:309-15.

4. Kouchoukos NT, Wareing TH, Murphy SF. Sixteen-year experience with aortic root replacement. Results of 172 operations. Ann Surg 1991; 214:308-20.

5. Strauch JT, Spielvogel D, Lansman SL. Long-term integrity of teflon felt-supported suture lines in aortic surgery. Ann Thorac Surg 2005 Mar; 79(3):796-800.

6. Milano AD, Pratali S, Mecozzi G, Boraschi P, Braccini G, Magagnini E, Bortolotti U. Fate of coronary ostial anastomoses after the modified Bentall procedure. Ann Thorac Surg 2003 Jun; 75(6):1797-801.

7. Dossche KM, Schepens MAAM, Morshuis WJ, Brutel de la Riviere A, Knaepen PJ, Vermeulen FEE. A 23-year experience with composite valve graft replacement of the aortic root. Ann Thorac Surg 1999; 67:1070-7.

8. Schachner T, Vertacnik K, Nagiller J. Factors associated with mortality and long time survival in patients undergoing modified Bentall operations. J Cardiovasc Surg (Torino) 2005 Oct; 46(5):449-55.

9. Ruvolo G, Fattouch K, Sinatra R. Factors influencing immediate and long-term results after button's technique. J Cardiovasc Surg (Torino) 2002; 43(3):337-43.

10. Schepens MAAM, Dossche KM, Morshuis WJ. Reoperations on the Ascending Aorta and Aortic Root: Pitfalls and Results in 134 Patients. Ann Thorac Surg 1999; 68:1676-80.

11. Omeroglu SN, Mansuroglu D, Goksedef D, et al. Ultrafast computed tomography in management of post-bentall aortic root pseudoaneurysm repair. Tex Heart Inst J. 2005; 32(1):91-4. 